\title{
Genome Amplification and Gene Expression in the Ciliate Macronucleus
}

\author{
Sally Allen ${ }^{1}$ and Ian Gibson ${ }^{2}$
}

Received 26 May 1971-Final 27 Oct. 1971

The focus of this review is on the micronucleus and macronucleus in the ciliated protozoa and the organization and function of the DNA molecules within them. We present (1) some of the structural and functional differences which are known, (2) the genetic evidence for macronuclear units, (3) two hypotheses for the organization of the DNA molecules in the macronucleus to explain these units, and (4) experiments designed to discriminate between these hypotheses. We conclude that the size of the genome is not reduced in the macronucleus and that there are 45 copies of the haploid genome present in the macronucleus of normal strains of Tetrahymena pyriformis and 800 copies in the macronucleus of Paramecium aurelia. The ciliate genome is relatively simple in terms of repeated sequences. However, not all copies of the genes present in the macronucleus may be identical since fractions of differing thermal stability appear after renaturation.

\section{INTRODUCTION}

Most ciliated protozoa possess two types of nuclei, a micronucleus and a macronucleus, the relative number varying in different species. Despite their common origin, the two types of nuclei differ structurally, functionally, and in their length of tenure within the cell. In the higher ciliates, the macronucleus

The work reported in this paper has been supported by a research grant, GM 15879 , from the National Institute of General Medical Sciences, U.S. Public Health Service, and by grants from the Science and Medical Research Councils of Great Britain. We are also grateful to the Center for Human Growth and Development, University of Michigan, for a summer fellowship facilitating collaboration.

${ }^{1}$ Departments of Botany and Zoology, University of Michigan, Ann Arbor, Michigan.

${ }^{2}$ School of Biological Sciences, University of East Anglia, Norwich, England. 
is usually much larger than the micronucleus and this is mirrored by the relative amounts of DNA contained within them. Well-defined chromosomes have been observed in the micronucleus, but they are rarely observed in the mature macronucleus. Definition of the relative roles of these nuclei in the life of the organism must therefore take into consideration not only the difference in total amount of DNA but also possible differences in the organization and function of the DNA molecules within them. We know there are units of some type in the macronucleus which segregate and lead to irreversible changes in phenotype among cells within a clone. In this review, we shall describe briefly (1) some of the differences between the two nuclei, (2) genetic evidence for macronuclear units, (3) two hypotheses for the organization of the DNA molecules in the macronucleus to explain these units, and (4) experiments designed to discriminate between the two hypotheses.

\section{DIFFERENCES BETWEEN MICRONUCLEUS AND MACRONUCLEUS}

Both nuclei are derived from a single diploid nucleus produced from the fusion of two haploid nuclei. In the higher ciliates, many rounds of DNA replication occur in the developing macronucleus. The mature macronucleus may possess anywhere from 8.2 to 6575 times the amount of micronuclear DNA, depending upon the organism (Raikov, 1969). In Tetrahymena pyriformis and Paramecium aurelia, the ratios are 20 and 430 times the diploid amount (Cleffmann, 1967; McDonald, 1972; Woodard et al., 1966, 1968). DNA synthesis is regulated independently in the two nuclei, although it may occur concomitantly in the cell cycle in some species such as $P$. aurelia or at different times in such species as T. pyriformis (Kimball, 1964; Prescott and Stone, 1967). The total amount of DNA may fluctuate in the macronucleus in different cells, and in some species such as T. pyriformis chromatin is extruded following the overproduction of DNA (Cleffmann, 1967; Kimball, 1967; Scherbaum et al., 1958). During the vegetative portion of the life cycle, the majority of genes are only active when present in the macronucleus (Allen, 1967; Sonneborn, 1954; Pasternak, 1967; Rao and Prescott, 1967; Ammermann, 1970; Murti and Prescott, 1970; Nanney, 1957; Wells, 1961). This nucleus is, however, discarded when the micronucleus undergoes meiosis, and a new macronucleus is generated from products of the micronucleus.

Chromosomes have been observed cytologically in the micronucleus, and they undergo mitotic and meiotic divisions. T. pyriformis has five pairs of chromosomes (Ray, 1956), while different strains of $P$. aurelia have numbers ranging from 30 to 63 pairs (Dippell, 1954; Jones, 1956; Košciuszko, 1965). Genetic experiments have corroborated cytological observations (Sonneborn, 
1947), and linkage groups have been identified, but in no case have these groups been localized to particular chromosomes (Allen, 1964; Beisson and Rossignol, 1969). Well-developed chromosome structures in the macronucleus are usually limited to certain stages of development in certain species of ciliates (Raikov, 1969). The mature macronucleus emerges as Feulgenpositive, chromosome-like fibrils are associated with DNA-containing small bodies, and in some species bundles of chromosomes seem to appear. Aggregates of different types have been reported and interpreted as representing whole genomes (Grell, 1964; Raikov, 1962; Wolfe, 1967; Nilsson, 1970). At present, we do not really know if the DNA-containing structures are fragments of chromosomes, whole chromosomes, or aggregates of chromosomes. Recent evidence suggests that the polytene chromosomes observed during the development of the macronucleus of certain hypotrichs break down into fragments (Ammermann, 1971; Kloetzel, 1970). These polytene chromosomes have a structure that departs from the typical insect pattern in that the individual bands are separated from each other by fibrous material (Kloetzel, 1970). At the time DNA is degraded, these compartments swell and fall apart from each other, and the individual chromosomes disappear. Rao and Ammermann (1970) and Kloetzel (1970) point out that the degradation of DNA may be differential, with the result that, following resynthesis of DNA, not all of the molecules present in the original micronucleus may be found in the mature macronucleus.

\section{GENETIC EVIDENCE FOR MACRONUCLEAR UNITS}

The behavior of the macronucleus has been studied by geneticists in Paramecium and Tetrahymena by looking at the asexual fissions within a clone. Phenotypic differences occur among cells within a clone, and these are determined by macronuclear differences. In Paramecium, mating types segregate from each other at the time when macronuclei segregate (Sonneborn, 1937). In Tetrahymena, intraclonal variation occurs in heterozygotes, and some cells have parental phenotypes (Nanney, 1964; Allen and Gibson, 1972). In these organisms, the phenotypic changes persist as long as the macronucleus persists.

The segregation of differentiated cell types has been observed for five different genes in heterozygotes and for the mating types in homozygotes in T. pyriformis (Allen, 1971; Nanny, 1964). After an initial number of fissions, the number of which is gene specific, the differentiated types begin to appear. Eventually, the rate at which they are produced approaches a value which is similar for all genes. These observations suggested that there are a number of units present in the macronucleus. If there are different types of units ( $A$ and $a$ ), segregation is explained as the appearance of daughter macro- 
nuclei which have only one of the types of units (all $A$ or all $a$ ). A mathematical model was devised by Schensted (1958) in which the rate of production of differentiated cell types at equilibrium was related to the number of units by the following equation:

$$
R_{f}=1(2 N-1)
$$

where $R_{f}$ is the rate per fission and $N$ is the number of units. If $R_{f}$ is equal to 0.0113 , as has been determined experimentally for several of the genes, then $N$ is equal to 45 .

Differentiated cell types begin to appear at different fissions for different allelic pairs in heterozygotes. Some, like the $\mathrm{H}$-serotype phenotypes, appeared within the first few fissions (Nanney et al., 1964), while cell types of different phosphatases specified by the $P-1$ alleles did not appear until at least 50 fissions after conjugation (Allen, 1971). Here, it is important to note that the persistence of the "diploid" (heterozygous) state is gene specific and cannot be a random process.

The gene-specific character of the time of appearance of differentiated cell types is set off from the nonspecific character of the rate at which the types are produced once they begin to appear. The first event is referred to as "determination" and involves the selection for expression of one of the alleles. The second event is referred to as "assortment" and involves the segregation-out of the units.

Determination is gene specific and irreversible and occurs even when the gene is not expressed phenotypically. Linked genes behave independently. This last observation is important because it localizes the site of action of the determination process to the individual gene or to short chromosome fragments.

The genetic evidence not only suggests that there are units in the macronucleus, but it sets certain limits as to the nature of these units. The genespecific character of determination and the fact that the diploid state persists for many fissions for some but not other genes make any simple hypothesis involving "haploid genomes" or random chromosome segregation untenable.

\section{HYPOTHESES FOR THE ORGANIZATION OF MACRONUCLEAR DNA MOLECULES}

Any hypothesis must take into consideration the relative amounts of DNA in the two types of nuclei, the size of the genome present therein, and, most important, the genetic observations. Two hypotheses have been developed which differ in the nature of the macronuclear units and in the process of determination. They agree in localizing the specificity of determination to the gene itself. In the first hypothesis, the units are diploid genomes (Sonneborn, 
Table I. Distribution of Amounts of DNA Within a Single Cell ${ }^{a}$

\begin{tabular}{|c|c|c|c|c|}
\hline Organism & Source & $\times 10^{-12} \mathrm{~g}$ & $\begin{array}{l}\times 10^{11} \\
\text { daltons }\end{array}$ & Percent \\
\hline \multirow{4}{*}{$\begin{array}{l}\text { T. pyriformis } \\
1 / \text { "mating type I" }\end{array}$} & G1 macronucleus & 10.16 & 61.0 & 89.0 \\
\hline & G2 micronucleus & 0.86 & 5.2 & 7.5 \\
\hline & Mitochondria & 0.40 & 2.4 & 3.5 \\
\hline & Total DNA per cell & 11.42 & 68.6 & 100.0 \\
\hline \multirow{4}{*}{$\begin{array}{l}P \text {. aurelia } \\
1 / 540\end{array}$} & G1 macronucleus & 252.00 & 1512.0 & 98.0 \\
\hline & G1 micronucleus $(\times 2)$ & 1.26 & 7.6 & 0.5 \\
\hline & Mitochondria & 3.97 & 23.8 & 1.5 \\
\hline & Total DNA per cell & 257.23 & 1543.4 & 100.0 \\
\hline
\end{tabular}

${ }^{a}$ Amounts given for T. pyriformis are based on measurements reported by Woodard et al. (1968) for the G1 and G2 macronuclei $\left(10.16 \pm 0.33 \times 10^{-12} \mathrm{~g}\right.$ and $21.29 \pm 1.27 \times$ $\left.10^{-12} \mathrm{~g}\right)$ and the $\mathrm{G} 2$ micronucleus $\left(0.86 \pm 0.03 \times 10^{-12} \mathrm{~g}\right)$ using rat liver nuclei as a standard reference. The total amount of mitochondrial DNA was calculated from data reported by Suyama (1966) and Suyama and Miura (1968) by the following considerations. Each mitochondrial DNA molecule contains $3.4 \times 10^{7}$ daltons, and there are an average of seven molecules per mitochondrion. If there are 1000 mitochondria per cell, we arrive at a total amount of $2.4 \times 10^{11}$ daltons of mitochondrial DNA per cell. The total DNA per cell was reported to be $15.7 \times 10^{-12} \mathrm{~g}$ (mean of four determinations) or $94.2 \times 10^{11}$ daltons in exponentially growing cells of the amicronucleate strain GL (Scherbaum et al., 1959). Assuming that the average exponential cell has 1.4 times as much DNA as the G1 cell leads to an estimate of $11.2 \times 10^{-12} \mathrm{~g}$ or $67 \times 10^{11}$ daltons per G1 cell. We have ignored the possible contribution by kinetosomal DNA to the total. If this were $5 \%$, it would not lower significantly the percentages shown above. Amounts given for P. aurelia were obtained by measurements using bull sperm as the standard reference. The value for the G1 micronucleus was $0.63 \pm 0.048 \times 10^{-12} \mathrm{~g}$ and for the $\mathrm{G} 1$ and $\mathrm{G} 2$ macronuclei $25.2 \pm 0.38 \times 10^{11} \mathrm{~g}$ and $51.2 \pm 0.86 \times 10^{11} \mathrm{~g}$, respectively. The total amount of mitochondrial DNA was calculated assuming 10,000 mitochondria per cell and the values per mitochondrion obtained by Suyama for Tetrahymena. The total DNA per cell was reported to be $1.71 \times 10^{-10} \mathrm{~g}\left(1026 \times 10^{11}\right.$ daltons) in stock 299 , syngen 8 (Soldo et al., 1970), whereas higher values, ranging between $2.64-3.52 \times 10^{-10} \mathrm{~g}\left(1584-2112 \times 10^{11}\right.$ daltons), were reported for stock 51, syngen 4, by Behme and Berger (1970). The latter workers estimated that the size of the haploid genome ranged between 3.07-4.09 $\times 10^{-13}$ $\mathrm{g}\left(1.8-2.4 \times 10^{11}\right.$ daltons). Again, we have ignored the contribution of kinetosomal DNA to the total in calculating the distribution of DNA.

1947) and determination involves differential gene activation (Nanney, 1964, 1968). In the second hypothesis, the units are chromosome fragments and determination involves differential gene replication (Allen and Gibson, 1972).

With the first hypothesis, 45 diploid genomes (or subnuclei) would be present in the macronucleus of $T$. pyriformis immediately after division. At a particular fission which is gene specific, each subnucleus is determined by a process referred to as "allelic repression." During this process, one of the alleles at each locus becomes permanently inactivated by some regulatory event, but which allele is inactivated may differ in different subnuclei. With 


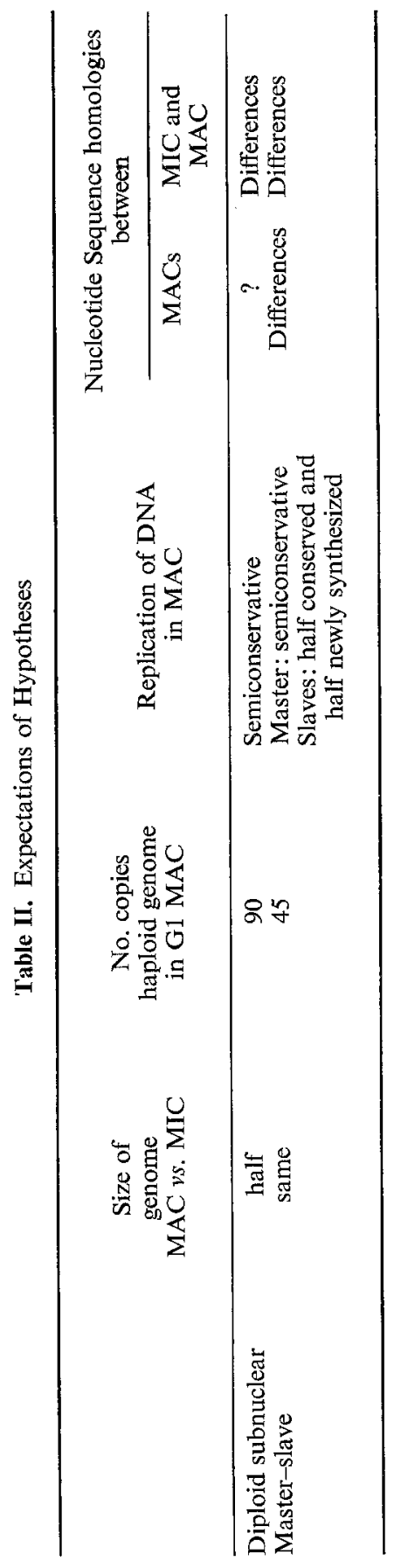


random segregation of the subnuclei from each other during macronuclear fissions, nuclei eventually appear having a full complement of subnuclei all differentiated for one of the alleles. Cell lines with different phenotypes should have exactly the same DNA nucleotide sequences, and there should be no qualitative differences in the DNA molecules of the cells directly attributable to the phenotypic differentiation.

Forty-five diploid genomes or 90 copies of the haploid genome would be expected in the G1 macronucleus. As shown in Table I, the ratio of the amount of DNA in the macronucleus compared to the diploid micronucleus is 23.7. This amount of DNA would only be enough for 45 copies of the haploid genome. To accommodate this observation, Nanney (personal communication) has recently proposed that as the macronucleus develops, only half the genome is replicated, and 90 copies of this half are made.

The other hypothesis assumes that the chromosomes fragment during the development of the macronucleus. These fragments then synthesize a number of nonreplicating copies. During each interfission period, the fragments, or "masters", replicate once, but the copies, or "slave," do not; instead, new slaves are synthesized by differential replication of the master. Each allele is present once as a master and as a number of slave copies, the total number of slaves being held to 90 for each pair of alleles. During cell division, the slaves are distributed at random, each daughter nucleus receiving a total of 45 slaves. Should one of the masters fail to replicate or to produce slaves, a cell is produced without an allele represented as a master, or a functional master, but a certain number of copies of the allele are still present as slaves. In subsequent fissions, these slaves would be diluted out and then only the other allele would be expressed. Cells retaining both masters would give off descendants lacking one of the masters at a particular rate. With this hypothesis, determination begins at a particular fission but continues in subsequent fissions. Here, we would expect to find qualitative differences in the DNA molecules correlated with different cell types within a clone.

A. total of 45 copies of both homologous masters or 45 copies of the haploid genome would be expected in the G1 macronucleus. With this hypothesis, then, it is not necessary to assume a smaller genome size.

The two hypotheses differ in important ways open to experimental attack. Table II shows how each differs with regard to the organization, replication, and nucleotide sequence homologies of the DNA molecules in the macronucleus. With the latest version of the subnuclear hypothesis, we would expect a genome size difference between the micronucleus and macronucleus and about 90 copies of this reduced genome in the G1 macronucleus. With the master-slave hypothesis, we would expect a similar genome size in both types of nuclei and 45 copies of the genome in the G1 macronucleus.

A further difference between the hypotheses concerns the mode of 

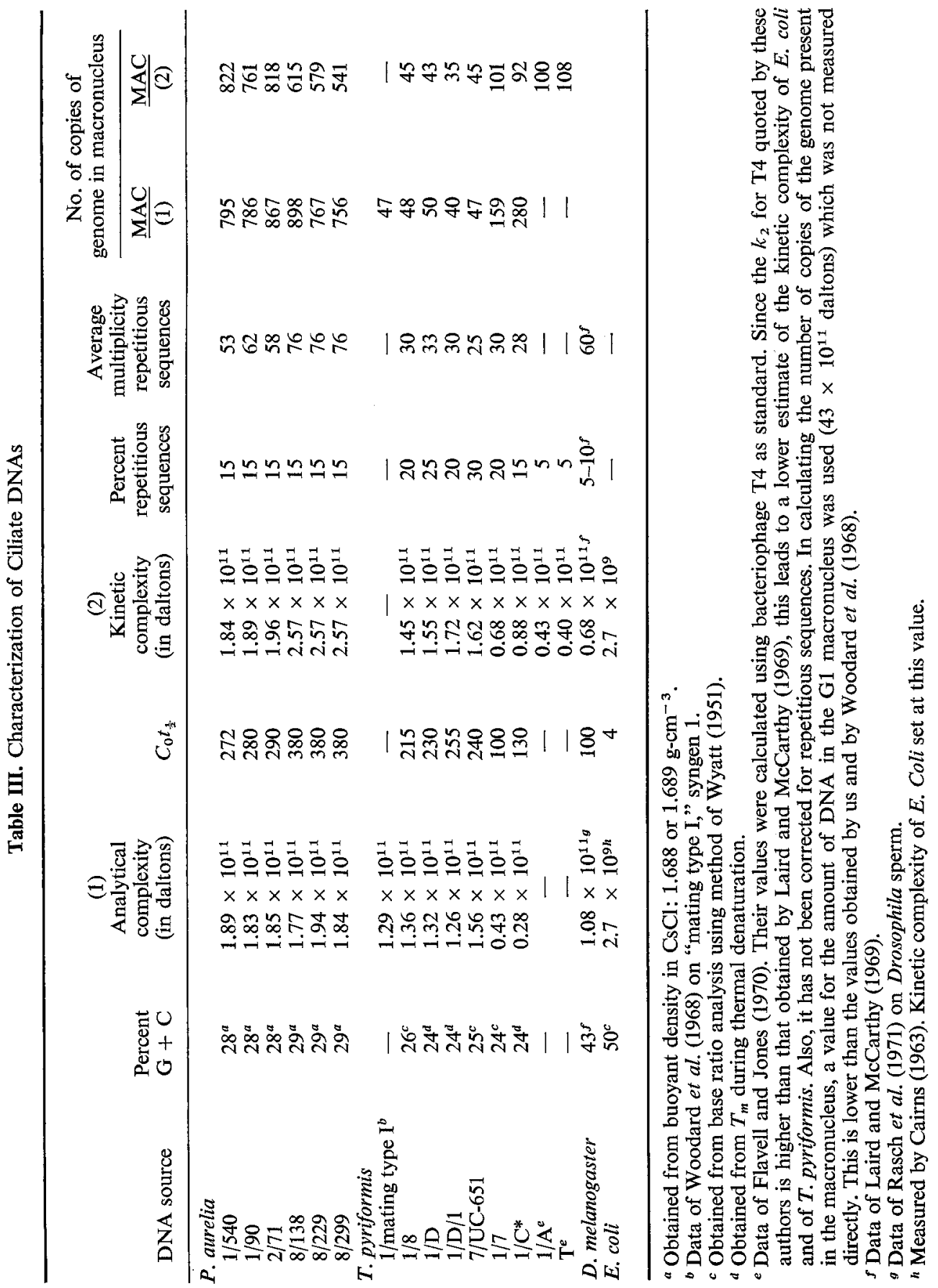
replication of the DNA molecules that make up the units. In the subnuclear hypothesis, semiconservative replication of the DNA of the subnuclei would be expected. With the master-slave hypothesis, since the slaves make up a large percentage of the DNA and cannot replicate, some of the DNA should be conserved.

A final point of difference between the two hypotheses involves the DNA nucleotide sequences present in the differentiated macronucleus. With the master-slave hypothesis, we would predict the generation of qualitative differences in the DNA molecules within clones due to differences among macronuclei, and these differences should be correlated with the differentiated phenotypes. Moreover, these differences should increase as a function of fissions so that more heterogeneity develops within a clone in time. In addition, we would predict differences between the micronucleus and macronucleus within the same cell. With the newest version of the subnuclear hypothesis, we would also expect differences between the micronucleus and macronucleus, but it is not clear whether we might expect to observe differences among macronuclei. The latter depends upon what happens to the half of the genome not replicated during the development of the macronucleus. In any event, we would not expect differences to be correlated with the phenotypic differences among clones.

Some of these predictions have been tested experimentally. These experiments are described in the next section.

\section{EXPERIMENTAL}

\section{Genome Size in the Micronucleus and Macronucleus}

Cytophotometric measurements of DNA amounts in the two types of nuclei relative to bull sperm give the size of the genome in the micronucleus (analytical complexity) and the total amount of DNA in the macronucleus. Renaturation experiments give the size of the genome in the macronucleus (kinetic complexity; see Wetmur and Davidson, 1968), assuming that at least $89 \%$ of the DNA molecules are derived from the macronucleus (see Table I). Our study included six stocks of $P$. aurelia and six strains of $T$. pyriformis. Some of the strains are distantly related and belong to different breeding groups (syngens), while others can exchange genes and belong to the same syngen. ${ }^{3}$ Four of the strains of $T$. pyriformis had normal-sized micronuclei, while two had smaller defective micronuclei $\left(1 / 7\right.$ and $\left.1 / \mathrm{C}^{*}\right)$.

Under the column headed "analytical complexity" in Table III are listed

${ }^{3}$ We have used six strains of $T$. pyriformis: strains $7,8, \mathrm{C}^{*}, \mathrm{D}, \mathrm{D} / 1$ (congenic with $\mathrm{D}$ ) in syngen 1, and UC-651 in syngen 7. In the tables and figures, these will be abbreviated as $1 / 7,1 / 8,1 / \mathrm{C}^{*}, 1 / \mathrm{D}, 1 / \mathrm{D} / 1$, and $7 / \mathrm{UC}-651$. Six stocks of $P$. aurelia were used: stocks 90 and 540 in syngen 1, stock 71 in syngen 2, and stocks 138, 229, and 299 in syngen 8. In the tables and figures, these will be abbreviated as $1 / 90,1 / 540,2 / 71,8 / 138,8 / 229$, and 8/299. A seventh stock 1/60 was used in the experiments described in Fig. 3 . 


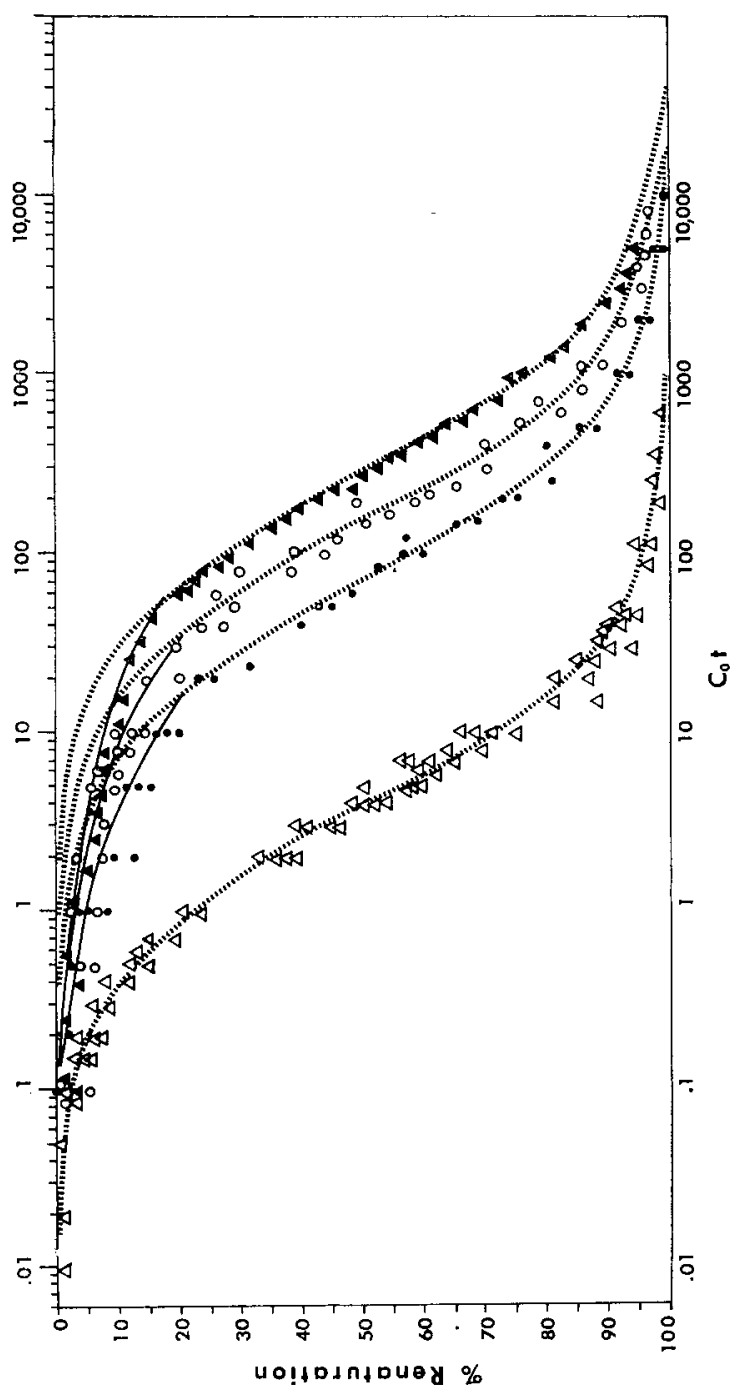

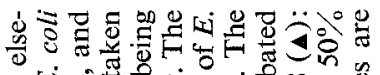

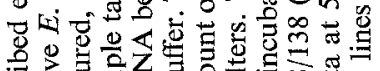

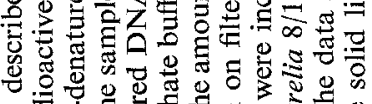

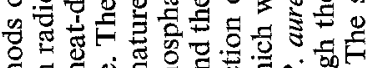

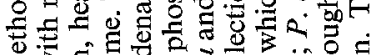

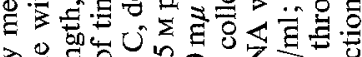

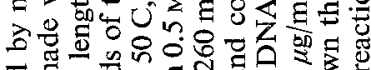
可

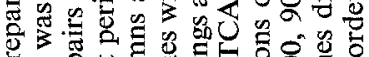

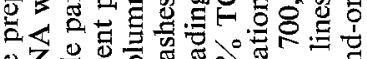

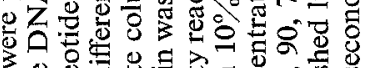

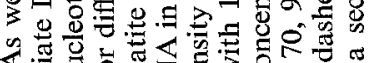

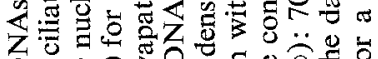

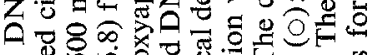
उ के

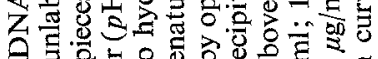

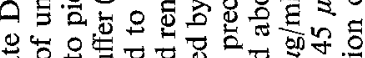

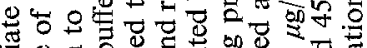

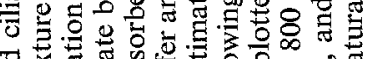

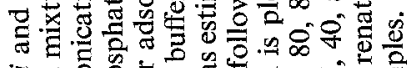
亏ัँ

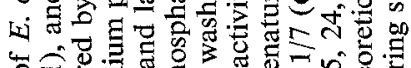
tô. पूर

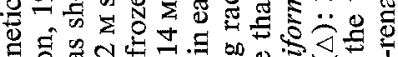

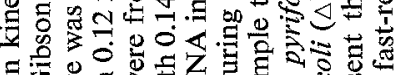

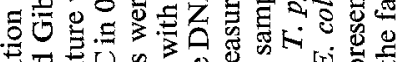
t马.

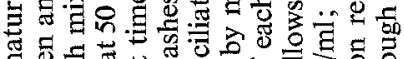

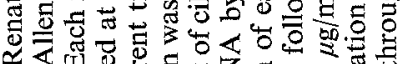

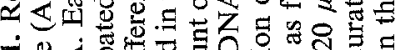
-

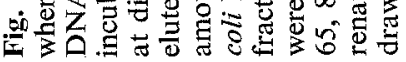


the values we have found for each of the strains. The six stocks of $P$. aurelia have values between $1.77-1.94 \times 10^{11}$ daltons (mean, $1.85 \times 10^{11}$ daltons), and these values are all bigger than any observed for $T$. pyriformis. The four strains of Tetrahymena with normal-sized micronuclei $(1 / 8,1 / \mathrm{D}, 1 / \mathrm{D} / 1$, and 7/UC-651) have values ranging between $1.26-1.56 \times 10^{11}$ daltons. The mean for strains in syngen 1 is $1.31 \times 10^{11}$ daltons, a figure similar to that reported by Woodard et al. (1968) for "mating type I" in syngen 1 . The other two strains in syngen $1\left(1 / 7\right.$ and $\left.1 / C^{*}\right)$ have visibly smaller micronuclei, and the values for analytical complexity are much reduced in these strains $(0.43$ and $0.28 \times$ $10^{11}$ daltons). Both of these strains are in the process of losing their micronuclei, a type of behavior which occurs in certain genotypes (Nanney, 1957; Allen et al., 1967).

In our renaturation experiments, we made a mixture of each ciliate DNA with radioactive Escherichia coli DNA, sheared the mixture, denatured it, and incubated it under optimal renaturation conditions, and assayed samples using salt chromatography on hydroxyapatite (Britten and Kohne, 1968). The $E$, coli DNA serves as an internal marker against which we can compare the renaturation of the ciliate DNA and calculate the genome size.

The results are shown in Fig. 1 and Table III. In the figure, we have indicated the curve expected for an idealized second-order reaction for each source of DNA. In the case of the protozoa, the reaction of $15-30 \%$ of the molecules is faster than that expected from a second-order reaction, a behavior expected of repeated sequences. The other $70-85 \%$ of the molecules follow the second-order reaction curve and represent unique sequences. No heterogeneity was observed in the more slowly renaturing population. Such heterogeneity with regard to renaturation might have been expected if half the genome in the macronucleus were present as 90 identical copies and the other half as single copies.

By normalizing the two groups of DNA molecules to $100 \%$ (see Laird and McCarthy, 1969), we can obtain the $C_{0} t$ values at half renaturation for repeated and unique sequences. This allows an estimate of the average multiplicity in the repeated sequence fraction for each source of DNA and is given in Table III.

The $C_{0} t_{1 / 2}$ values for unique sequences are also given in Table III (fourth column). By using an equation which relates $C_{0} t_{1 / 2}$ to genome size, we can calculate the size of the haploid genome in the macronucleus for each of our strains. These values are found in the column headed "kinetic complexity." The six stocks of $P$. aurelia have values between $1.84-2.57 \times 10^{11}$ daltons, while the six strains of $T$. pyriformis have values between $0.68-1.72 \times$ $10^{11}$ daltons. Recent experiments with purified unique sequences from strains $1 / \mathrm{D}$ and $1 / \mathrm{D} / 1$ give $C_{0} t_{1 / 2}$ values of 200 and a kinetic complexity of $1.35 \times$ $10^{11}$ daltons. 
All of the Paramecium stocks have bigger genomes than those found in Tetrahymena. Among the stocks of Paramecium, the ones from syngen 8 appear to have a significantly larger value than those from syngens 1 and 2 . In Tetrahymena, two of the strains $\left(1 / 7\right.$ and $\left.1 / \mathrm{C}^{*}\right)$ have a genome approximately half that of the other strains. When strains 7 and UC-651, of different genome sizes and from different syngens, were run together on a hydroxyapatite column, and one was monitored by radioactivity and the other by optical density, the renaturation kinetics of each sample in the mixture was the same as that of each sample when analyzed separately. ${ }^{4}$

When measurements of analytical and kinetic complexity are compared on the same strain, we find that in general there is agreement between the two measures [Table III: (1) vs. (2)]. If anything, the values for kinetic complexity are larger than those for analytical complexity. This is particularly pronounced for the three stocks of $P$. aurelia in syngen 8 . In the case of the two defective strains of $T$. pyriformis with a reduced micronuclear genome, the macronuclear genome is also reduced but not to the same extent. Here, there appear to be mechanisms which affect both the micronucleus and macronucleus to bring about loss of DNA molecules from both types of nuclei. In normal strains of both Tetrahymena and Paramecium, this does not seem to occur, and the genome size does not seem to be reduced in the macronucleus.

\section{Number of Copies of the Genome in the Macronucleus}

Cytophotometric measurement of the total amount of DNA in the G1 macronucleus was carried out on each of the strains. For Paramecium, this averages $15.04 \times 10^{13}$ daltons $\left(13.92-16.04 \times 10^{13}\right.$ daltons in the different stocks; Table I shows the data for 1/540). For Tetrahymena, Woodard et al. (1968) found that the G1 macronucleus contained $61.0 \times 10^{11}$ daltons of DNA (Table I). We obtained similar values for the strains used in our studies $\left(60.4-73.0 \times 10^{11}\right.$ daltons for strains with normal micronuclei and 68.4-81.1 $\times 10^{11}$ daltons for strains with defective micronuclei). Using these values, we can divide by the values found for analytical or kinetic complexity to obtain the number of copies of the haploid genome present in the macronucleus. These calculations are shown in the last two columns of Table III. Except for syngen 8, there is agreement in Paramecium between the two measures, and there appear to be about 800 copies of the genome in the macronucleus. This is the same order of magnitude found by Woodard et al. (1966) for syngen 4 (860 copies). For the normal strains of Tetrahymena, the

${ }^{4}$ These two strains in syngens 1 and 7 appear to share very few nucleotide sequences. Thus, the position of the $C_{0} t$ curve of the radioactive DNA present in the mixture $(1: 10)$ was not affected by the unlabeled DNA. In contrast, when strains 7 and 8 from syngen 1 were run together in a ratio of $1: 20$, the position of the $C_{0} t$ curve for the radioactive DNA $(1 / 7)$ was noticeably affected $\left(C_{0} t_{1,2}\right.$ equal to 8 instead of 70$)$. 
number of copies is between 40-50, and there is agreement between the two measures and with the number of copies estimated by Woodard et al. (1968) for "mating type I" in syngen 1. For the defective strains, the number of copies appears to be at least doubled. Note that our figures for the defective strains are similar to the calculations made by Flavell and Jones (1970), and it seems likely that the strains they used may not have had normal micronuclei.

\section{Heterogeneity Within and Between Genomes}

Information about the product of renaturation is necessary before meaningful comparisons can be made of nucleotide sequence differences between genomes. That is, we need to know if there is heterogeneity in terms of
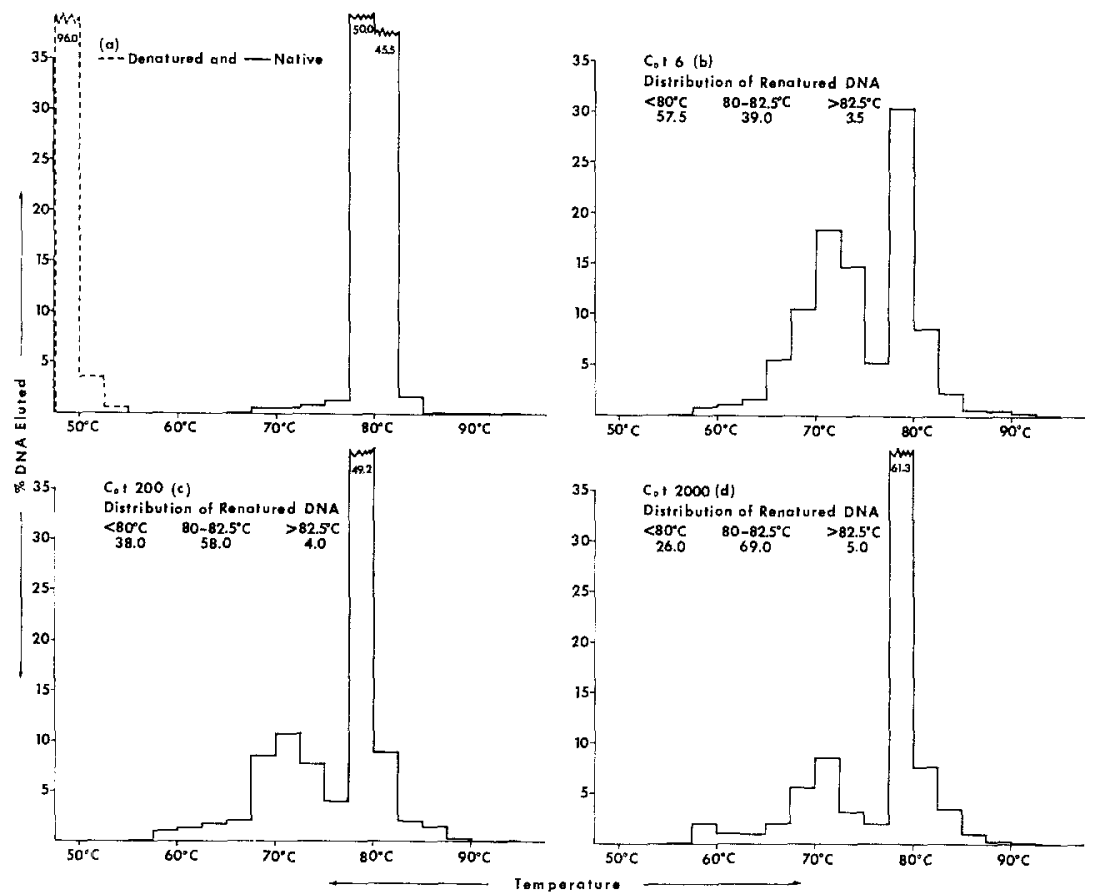

Fig. 2. Thermal chromatography of native, denatured, and renatured DNA from $P$. aurelia $8 / 138(\mathrm{a}-\mathrm{d})$ and $T$. pyriformis $1 / 7(\mathrm{e}-\mathrm{h})$. Native and denatured DNA $(\mathrm{a}, \mathrm{e})$ and DNA molecules renatured to particular $C_{0} t$ values $(\mathrm{b}: 6 ; \mathrm{e}: 200 ; \mathrm{d}: 2000 ; \mathrm{f}: 2 ; \mathrm{g}: 200$; $\mathrm{h}: 2000)$ containing $985 \mu \mathrm{g}$ (Paramecium) or $950 \mu \mathrm{g}$ (Tetrahymena) were adsorbed to hydroxyapatite columns at $50 \mathrm{C}$, and thermal elution was carried out using $0.14 \mathrm{M}$ phosphate buffer at 2 Cincrements between 50 and $95 \mathrm{C}$. A final series of washes was carried out with $0.5 \mathrm{~m}$ phosphate buffer at $90 \mathrm{C}$. The eluates were monitored by optical density at $260 \mathrm{~m} \mu$. Radioactive $E$. coli. DNA was present in all experiments and was assayed after precipitating samples in the presence of methylated albumin with $10 \%$ 


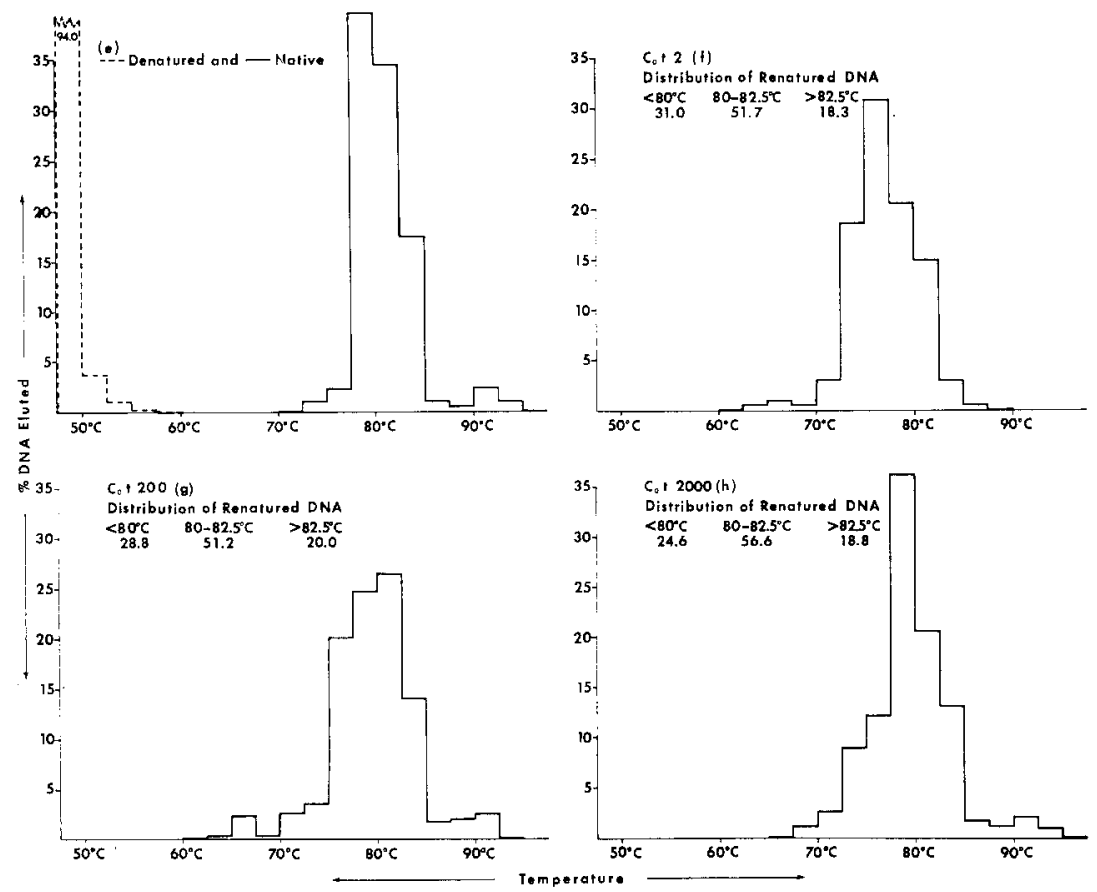

Fig. 2. Continued.

TCA and collecting the precipitates on filters. The filters were dried, placed in scintillation fluid, and counted in a Tri-Carb scintillation counter. Renatured E. coli molecules had an elution profile similar to that of native DNA, with a peak at 90-92 C. The percentages of ciliate DNA in different fractions are based on the total population of molecules in (a) and (e) but only on the population of renatured molecules in (b,c,d) and $(f, g, h)$. In the insert, we show the distribution of these renatured molecules in regions of low, native, and high thermal stability.

nucleotide sequence differences within the genome, and, if there is, we can select specific fractions to increase the resolution of intergenome comparisons. For a simple genome, we would expect that most of the renatured molecules are in structures with native-like properties. If, as in other eukaryotic organisms, repeated sequences are involved, then a certain proportion of renatured molecules with thermal stabilities lower than those of native molecules might form due to mismatching of base pairs (Kohne, 1970). We have observed fractions with lowered thermal stabilities, but they seem to be appearing in the unique sequence fraction. This is a highly unorthodox finding, of which we are fully aware. Although lowered thermal stabilities usually are thought to indicate mismatching of base pairs, there are other possible reasons for this observation, including differences in base composition or in the distribution of base sequences which are present. 
The technique we used is thermal chromatography on hydroxyapatite columns (Britten and Kohne, 1966; see the legend to Fig. 2 for details). Various thermal fractions between 50 and $95 \mathrm{C}$ were collected and analyzed. In Fig. 2(a) we show the results with native and denatured, sheared Paramecium DNA $(8 / 138)$ and in Fig. $2(b, c, d)$ the distribution of renatured DNA formed at $C_{0} t$ values of 6, 200, and 2000. In Fig. 2(e), we show the results with native and denatured, sheared Tetrahymena DNA (1/7) and in Fig. 2 $(\mathrm{f}, \mathrm{g}, \mathrm{h})$ the distribution of renatured DNA formed at $C_{0} t$ values of 2, 200, and 2000. The majority of native DNA molecules elute at temperatures between 77.5 and $82.5 \mathrm{C}$, and the thermal profile indicates a single population of molecules. Denatured DNA elutes from the column at $50 \mathrm{C}$. Renatured DNA molecules show a heterogeneous distribution, some of which have native stabilities and other lower stabilities. A more discontinuous distribution of renatured molecules is observed in Paramecium compared to Tetrahymena, where two peaks are found, one at $73 \mathrm{C}$ and the other at $80 \mathrm{C}$. With increasing $C_{0} t$ values, the proportion of DNA found in the region of lower thermal stability decreases but not as rapidly as expected if this fraction included only repeated sequences. Moreover, if the repeated sequences are removed and the remainder incubated, these fractions still appear.

Qualitative and quantitative differences in these fractions are observed among stocks of Paramecium but not among strains of Tetrahymena. The amounts and types of fractions formed at $C_{0} t$ values of 1-2000 for each strain are shown in Table IV. Stocks 138 and 299 of $P$. aurelia have both the

Table IV. Distribution of Thermal Stabilities of Renatured DNA

\begin{tabular}{|c|c|c|c|c|c|}
\hline & \multicolumn{2}{|c|}{ Renatured } & \multirow[b]{2}{*}{$\begin{array}{l}<78 \mathrm{C} \\
(\%)\end{array}$} & \multirow[b]{2}{*}{$\begin{array}{c}78-82 \mathrm{C} \\
(\%)\end{array}$} & \multirow[b]{2}{*}{$\begin{array}{c}>82 \mathrm{C} \\
(\%)\end{array}$} \\
\hline & to $C_{0} t$ & $\begin{array}{c}\text { in } P B \\
(M)\end{array}$ & & & \\
\hline \multicolumn{6}{|l|}{ P. aurelia } \\
\hline $1 / 540$ & 2000 & 0.12 & 20 & 40 & 40 \\
\hline $1 / 90$ & 2000 & 0.12 & 18 & 52 & 30 \\
\hline $8 / 138$ & 2000 & 0.12 & 26 & 69 & 5 \\
\hline $8 / 299$ & 2000 & 0.12 & 20 & 73 & 7 \\
\hline \multicolumn{6}{|l|}{ T. pyriformis } \\
\hline $1 / 7$ & 2000 & 0.12 & 34 & 58 & 8 \\
\hline $1 / 8$ & 2000 & 0.12 & 31 & 62 & 7 \\
\hline $7 /$ UC-651 & 1000 & 0.12 & 35 & 56 & 9 \\
\hline $1 / C^{*}$ & $2520^{a}$ & $0.4^{b}$ & 40 & 50 & 10 \\
\hline $1 / \mathrm{D}$ & 1814 & 0.4 & 34 & 55 & 11 \\
\hline $1 / \mathrm{D} / 1$ & 1050 & 0.4 & 33 & 56 & 11 \\
\hline
\end{tabular}

a "Equivalent" $C_{0} t$ (see Britten and Smith, 1969).

${ }^{b}$ Parallel experiments were run in which the DNA was renatured in $0.12 \mathrm{M} \mathrm{PB}$, with similar distributions being observed. 

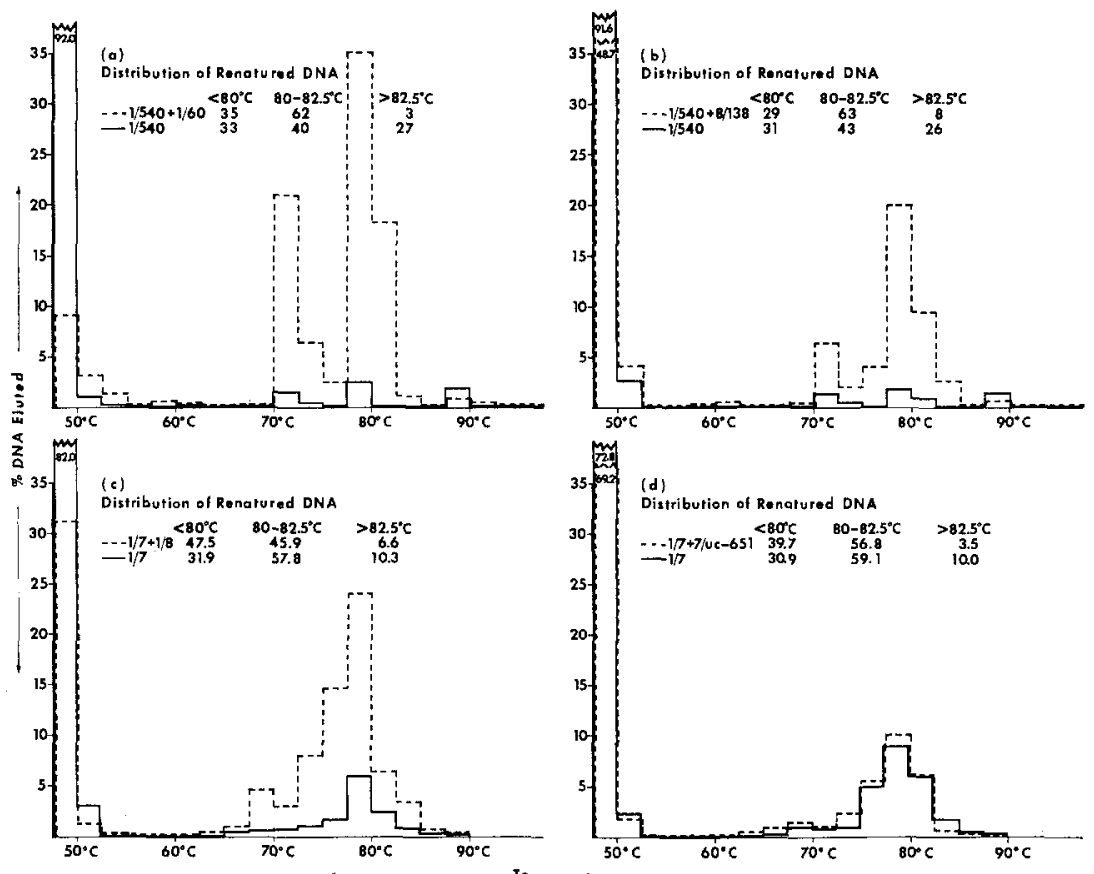

Fig. 3. Thermal chromatography of hybrids between strains of Paramecium and Tetrahymena. (a) $P$. aurelia $1 / 540$ to $1 / 60$; (b) $P$. aurelia $1 / 540$ to $8 / 138$; (c) $T$. pyriformis $1 / 7$ to $1 / 8$; (d) $T$. pyriformis $1 / 7$ to $7 /$ UC-651. In (a), radioactive DNA molecules from $1 / 540(4820 \mathrm{count} / \mathrm{min} / \mu \mathrm{g})$ were sheared by sonication, heat-denatured, and incubated to a $C_{0} t$ of 12.5 at $20 \mu \mathrm{g} / \mathrm{ml}, 50 \mathrm{C}$, in $0.12 \mathrm{M}$ sodium phosphate buffer (control). In the experimental series, they were incubated to the same $C_{0} t$ in the presence of sonicated, denatured DNA from 1/60 $(984 \mu \mathrm{g} / \mathrm{ml})$. The procedure outlined in Fig. 2 was followed. Fractions in the experimental series were monitored by optical density at $260 \mathrm{~m} \mu$ to detect the distribution of $1 / 60$ molecules; $1 / 540$ was assayed in the fractions by counting radioactivity. The results show that when radioactive 1/540 DNA was incubated on its own (control) only $6.6 \%$ of the molecules renatured. In the presence of $1 / 60,86.8 \%$ of the radioactive molecules renatured (experimental). Therefore, the percent homology between the two DNAs is $80.2 \%(86.8 \%-6.6 \%)$. In the insert, we show the distribution of these renatured molecules in regions of low, native, and high thermal stability. In (b), radioactive $1 / 540(20 \mu \mathrm{g} / \mathrm{ml}, 4820 \mathrm{count} / \mathrm{min} / \mu \mathrm{g})$ was incubated to a $C_{0} t$ of 12.5 alone or in the presence of sonicated, denatured DNA from $8 / 138(1 \mathrm{mg} / \mathrm{ml})$. Incubated by itself $5.8 \%$ renatured (control), but in the presence of $8 / 13847.1 \%$ renatured (experimental). The percent homology between $1 / 540$ and $8 / 138$ is then $41.3 \%$. In (c), radioactive $1 / 7(50 \mu \mathrm{g} / \mathrm{ml}, 12,000 \mathrm{count} / \mathrm{min} / \mu \mathrm{g})$ was incubated to a $C_{0} t$ of 10.5 alone or in the presence of sonicated, denatured DNA from $1 / 8(950 \mu \mathrm{g} / \mathrm{ml})$. The results show that incubated by itself $14.7 \%$ renatured but in the presence of $1 / 867.3 \%$ renatured. Therefore, the percent homology between $1 / 7$ and $1 / 8$ is $52.6 \%$. In (d), radioactive $1 / 7$ (46 $\mu \mathrm{g} / \mathrm{ml}, 12,000 \mathrm{count} / \mathrm{min} / \mu \mathrm{g}$ ) was incubated to a $C_{0} t$ of 20 alone or in the presence of sonicated, denatured DNA from 7/UC-651 $(456 \mu \mathrm{g} / \mathrm{ml})$. The results show that incubated by itself $25.0 \%$ renatured but in the presence of $7 / \mathrm{UC}-65129.0 \%$ renatured. The percent homology between $1 / 7$ and $7 / \mathrm{UC}-651$ is thus $4.0 \%$. 
73 and $80 \mathrm{C}$ fractions, and the amounts of each do not differ between strains. Stocks 540 and 90 have an extra fraction which elutes at $90 \mathrm{C}$, indicating renatured molecules with a greater thermal stability than native DNA. This fraction disappears if renaturation is carried out at $70 \mathrm{C}$. When stock 138 and 540 DNAs are each renatured at $70 \mathrm{C}$ to $C_{0} t 1000$, the $73 \mathrm{C}$ peak decreases by half and the native peak increases proportionately. In Tetrahymena, the thermal stability profiles of different strains are rather similar, with $31-40 \%$ of the DNA molecules being removed at temperatures less than $78 \mathrm{C}$, $50-62 \%$ at $78-82 \mathrm{C}$, and $8-11 \%$ at temperatures greater than $82 \mathrm{C}$. No effect on these distributions was observed if renaturation was carried out in high salt ( $0.4 \mathrm{M}$ phosphate buffer). This lack of effect of high salt was also observed when the product formed from renatured, purified unique sequences was examined.

The thermal fractions of both $P$. aurelia and $T$. pyriformis have been characterized in terms of $T_{m}$, hyperchromicity, their specificity when rechromatographed, and their buoyant density in neutral $\mathrm{CsCl}$ gradients. All fractions are double-stranded DNA molecules which differ in their stability to temperature and in their degree of hyperchromicity. Some have thermal stabilities and hyperchromicities similar to those of native molecules, but others have thermal stabilities and hyperchromicities lower than those of native molecules. On neutral $\mathrm{CsCl}$ gradients, fractions which differ in $T_{m}$ show similar buoyant densities, but the densities may be higher than that of native DNA, indicating the presence of some single-stranded regions. These observations are puzzling at the moment, particularly if the fractions represent unique sequences. The dichotomy between unique and repeated sequences may not be as sharp as is sometimes thought (see Southern, 1971). It is possible that the multiple copies of genes found in the macronucleus may not be identical. It is also possible that these fractions differ in base composition, although we cannot at the moment show it. Whatever the basis of these fractions, preliminary experiments indicate specificity in their pattern of hybridization with other fractions.

Fractions of low thermal stability are also seen in Paramecium and Tetrahymena when hybrid reactions are carried out between strains of the same or different syngens. In Fig. 3(a,b), we show the results of hybridization and a thermal analysis of the product formed between the DNA molecules from $1 / 540$ and $1 / 60$ and between $1 / 540$ and $8 / 138$ of $P$. aurelia. In Fig. 3 (c,d), we show the results with $1 / 7$ and $1 / 8$ and $1 / 7$ and $7 /$ UC-651 of $T$. pyriformis, respectively. In Fig. 3(a), there is $80 \%$ homology between the two strains in the same syngen of Paramecium and $35 \%$ of this involves sequences eluted at lower temperatures than native hybrid molecules. In Fig. 3(b), the two syngens show $41 \%$ homology, of which $29 \%$ is eluted in the lower temperature range. In Fig. 3(c), the two strains in the same syngen of $T$. 
pyriformis with different genome sizes have $53 \%$ of their sequences in common, and $48 \%$ of this involves hybrids with low thermal stability. In Fig. 3(d), 4\% homology is observed between the two syngens of Tetrahymena, $40 \%$ involving sequences of low thermal stability. These experiments indicate that the extent of the cross-reactions between syngens and strains of $P$. aurelia is higher than for T. pyriformis. A similar trend was found in earlier work involving syngens $1,2,4$, and 5 of $P$. aurelia and $1,8,9,10$, and 12 of T. pyriformis using the DNA-DNA agar or filter technique of hybridization. Here, we observed that the hybrid DNA molecules also had a low thermal stability (Allen and Gibson, 1967, 1972; Gibson, unpublished).

Fractions which differ in thermal stability appear in renatured DNA molecules both within and between genomes. At present, we do not know how the fractions formed within a genome relate to those formed between genomes. Only direct experiments using the fractions from different sources can settle this question.

\section{CONCLUSIONS}

1. Our observations on normal strains of $T$. pyriformis and $P$. aurelia do not support Nanney's idea of a reduced genome size in the macronucleus. A reduced genome size is necessary for the subnuclear hypothesis, but not for the master-slave hypothesis.

2. The values for the haploid genome size of $T$. pyriformis and $P$. aurelia fall into the same range as those of Drosophila and grasshopper DNA (Laird and McCarthy, 1969; Gibson and Hewitt, 1972).

3. The number of copies of the haploid genome in the G1 macronucleus is around 45 for normal strains of $T$. pyriformis and 800 for $P$. aurelia.

4. The ciliate genome is relatively simple, containing a few genes which can be detected as repeated sequences. Other genes are present as single copies, but it is possible that not all copies present in the macronucleus are identical, since fractions of differing thermal stability appear after rencturation.

5. These fractions may be confined to the macronuclear genome. Their characterization is in progress as well as hybridization experiments. We think they should be useful in looking for differences in nucleotide sequences specifically correlated with clonal differentiation. Congenic lines of $T$. pyriformis have been constructed (Allen and Lee, 1971), and we have begun looking at the DNA fractions from heterozygotes between these lines.

\section{REFERENCES}

Allen, S. L. (1964). Linkage studies in variety 1 of Tetrayhmena pyriformis: A first case of linkage in the ciliated protozoa. Genetics 49:617. 
Allen, S. L. (1967). Genomic exclusion: A rapid means for inducing homozygous diploid lines in Tetrahymena pyriformis, syngen 1. Science 155:575.

Allen, S. L. (1971). A late-determined gene in Tetrahymena heterozygotes. Genetics 68: 415.

Allen, S. L., and Gibson, I. (1967). Genetic homologies and drift within populations of DNA molecules. Science 158:523.

Allen, S. L., and Gibson, I. (1971). The purification of DNA from the genomes of Paramecium aurelia and Tetrahymena pyriformis. J. Protozool. 18:518.

Allen, S. L., and Gibson, I. (1972). Genetics of Tetrahymena. In Elliott, A. M. (ed.), Biology of Tetrahymena, Dowden, Hutchinson \& Ross, Stroudsburg. (in press).

Allen, S. L., and Lee, P. H. T. (1971). The preparation of congenic strains of Tetrahymena. J. Protozool. $18: 214$.

Allen, S. L., File, S. K., and Koch, S. L. (1967). Genomic exclusion in Tetrahymena. Genetics 55:823. (in press).

Ammerman, D. (1970). The micronucleus of the ciliate Stylonychia mytilus: its nucleic acid synthesis and its function. Exptl. Cell Res. 61:6.

Ammermann, D. (1971). Morphology and development of the macronuclei of the ciliates Stylonychia mytilus and Euplotes aediculatus. Chromosoma 33:209.

Behme, R. J., and Berger, J. D. (1970). The DNA content of Paramecium aurelia, stock 51. J. Frotozool. (Suppl.) 17:20.

Beisson, J., and Rossignol, M. (1969). The first case of linkage in Paramecium aurelia. Genet. Res. Camb. 13:85.

Britten, R. J., and Kohne, D. E. (1966). Nucleotide sequence repetition in DNA. Carnegie Inst. Wash. Year Book 65:78.

Britten, R. J., and Kohne, D. E. (1968). Repeated sequences in DNA. Science 161:529.

Britten, R. J., and Smith, J. (1969). A bovine genome. Carnegie Inst. Wash. Year Book 68: 378.

Cairns, J. (1963). The chromosome of Escherichia coli. Cold Spring Harbor Symp. Quant. Biol. 28:43.

Cleffmann, G. (1967). Regulierung der DNA-Menge im Makronucleus von Tetrahymena. Exptl. Cell Res. 50:193.

Dippell, R. V. (1954). A preliminary report on the chromosomal constitution of certain variety 4 races of Paramecium aurelia. Caryologia (Suppl.) 5:1109.

Flavell, R. A., and Jones, I. G. (1970). Kinetic complexity of Tetrahymena pyriformis nuclear deoxyribonucleic acid. Biochem. $J$. 116:155.

Gibson, I., and Hewitt, G. (1972). DNA sequences in the B chromosomes of grasshoppers. Nature New Biol.

Grell, K. G. (1964). The protozoan nucleus. In Brachet, J., and Mirsky, A. (eds.), The Cell, Vol. 6, Academic Press, New York, pp. 1-79.

Jones, K. W. (1956). Nuclear differentiation in Paramecium aurelia. Ph.D. thesis, Aberystwyth University, Wales.

Kimball, R. F. (1964). Physiological genetics of the ciliates. In Hutner, S. H. (ed.), Biochemistry and Physiology of Protozoa, Vol. III, Academic Press, New York, pp. 243-275.

Kimball, R. F. (1967). Persistent intraclonal variations in cell dry mass and DNA content in Paramecium aurelia. Exptl. Cell Res. 48:378.

Kloetzel, J. A. (1970). Compartmentalization of the developing macronucleus following conjugation in Stylonychia and Euplotes. J. Cell Biol, 47:395.

Kohne, D. E. (1970). Evolution of higher organism DNA. Quart. Rev. Biophys. 3:327.

Košciuszko, H. (1965). Karyologic and genetic investigations of syngen 1 of Paramecium aurelia. Folia Biol. 13:339.

Laird, C. D., and McCarthy (1969). Molecular characterization of the Drosophila genome. Genetics 63:865.

McDonald, B. B. (1972). Nucleic acids during vegetative growth and conjugation in Tetrahymena. In Elliott, A. M. (ed.), Biology of Tetrahymena, Dowden, Hutchinson \& Ross, Stroudsburg. (in press). 
Murti, K. G., and Prescott, D. M. (1970). Micronuclear ribonucleic acid in Tetrahymena pyriformis. J. Cell Biol. 47:460.

Nanney, D. L. (1957). Inbreeding degeneration in Tetrahymena. Genetics 42:137.

Nanney, D. L. (1964). Macronuclear differentiation and subnuclear assortment in ciliates. In Locke, M. (eds.), The Role of Chromosomes in Development, Academic Press, New York, pp. 253-273.

Nanney, D. L. (1968). Ciliate genetics: Patterns and programs of gene action. Ann. Rev. Genet. 2:121.

Nanney, D. L., Nagel, M. J., and Touchberry, R. W. (1964). The timing of H antigenic differentiation in Tetrahymena. J. Exptl. Zool. 155:25.

Nilsson, J. R. (1970). Suggestive structural evidence for macronuclear "subnuclei" in Tetrahymena pyriformis GL. J. Protozool. 17:539.

Pasternak, J. (1967). Differential genic activity in Paramecium aurelia. J. Exptl. Zool. 165: 395.

Prescott, D. M., and Stone, G. E. (1967). Replication and function of the protozoan nucleus. In Chen, T.-T. (ed.), Research in Protozoology, Vol. 2, Pergamon Press, New York, pp. 118-146.

Raikov, I. B. (1962). Der Kernapparat von Nassula ornata Ehrb. (Ciliata, Holotricha). Zur Frage über den Chromosomenauf bau des Makronucleus. Arch. Protistenk. 105: 463.

Raikov, I. B. (1969). Macronucleus of ciliates. In Chen. T.-T. (ed.), Research in Protozoology, Vol. 3, Pergamon Press, New York, pp. 1-128.

Rao, M. V. N., and Ammermann, D. (1970). Polytene chromosomes and nucleic acid metabolism during macronuclear development in Euplotes. Chromosoma 29:246.

Rao, M. V. N., and Prescott, D. M. (1967). Micronuclear RNA synthesis in Paramecium caudatum. J. Cell. Biol. $33: 281$.

Rasch, E. M., Barr, H. J., and Rasch, R. W. (1971). The DNA content of sperm of Drosophila melanogaster. Chromosoma 33:1.

Ray, C., Jr. (1956). Meiosis and nuclear behavior in Tetrahymena pyriformis. J. Protozool. 3:88.

Schensted, I. V. (1958). Model of subnuclear segregation in the macronucleus of ciliates. Am. Naturalist. 92:161.

Scherbaum, O. H., Louderback, A. L., and Jahn, T. L. (1958). The formation of subnuclear aggregates in normal and synchronized protozoan cells. Biol. Bull. 115:269.

Scherbaum, O. H., Louderback, A. L., and Jahn, T. L. (1959). DNA synthesis, phosphate content and growth in mass and volume in synchronously dividing cells. Exptl. Cell Res. 18:150.

Soldo, A. T., van Wagtendonk, W. J., and Godoy, G. A. (1970). Nucleic acid and protein content of purified endosymbiote particles of Paramecium aurelia. Biochim. Biophys. Acta 204:325.

Sonneborn, T. M. (1937). Sex, sex inheritance and sex determination in P. aurelia. Proc. Natl. Acad. Sci. 23:378.

Sonneborn, T. M. (1947). Recent advances in the genetics of Paramecium and Euplotes. Adv. Genet. 1:263.

Sonneborn, T. M. (1954). Is gene $K$ active in the micronucleus of Paramecium aurelia? Microbiol. Genet. Bull. 11:25.

Southern, E. M. (1971). Effects of sequence divergence on reassociation properties of repetitive DNA's. Nature New Biol. 232:82.

Suyama, Y. (1966). Mitochondrial deoxyribonucleic acid of Tetrahymena. Its partial physical characterization. Biochemistry 5:2214.

Suyama, Y., and Miura, K. (1968). Size and structural variations of mitochondrial DNA. Proc. Natl. Acad. Sci. 60:235.

Wells, C. (1961). Evidence for micronuclear function during vegetative growth and reproduction of the ciliate. Tetrahymena pyriformis. J. Protozool. 8:284.

Wetmur, J. G., and Davidson, N. (1968). Kinetics of renaturation of DNA. J. Mol. Biol. $31: 349$. 
Wolfe, J. (1967). Structural aspects of amitosis: A light and electron microscope study of the isolated macronuclei of Paramecium aurelia and Tetrahymena pyriformis. Chromosoma 23:59.

Woodard, J., Woodard, M., Gelber, B., and Swift, H. (1966). Cytochemical studies of conjugation in Paramecium aurelia. Exptl. Cell. Res 41:55.

Woodard, J., Gorovsky, M., and Kaneshiro, E. (1968). Macronuclear subnuclei of Tetrahymena. J. Cell Biol. 39:182a.

Wyatt, G. R. (1951). The purine and pyrimidine content of deoxypentose nucleic acids. Biochem. J. 48:584 